\title{
The Uniform Logic System of Business Efficiency Evaluation Methods
}

\author{
Mária Illés \\ Department of Business Economics, Faculty of Economics, University of Miskolc, Hungary
}

Copyright $\subseteq 418$ by authors, all rights reserved. Authors agree that this article remains permanently open access under the terms of the Creative Commons Attribution License 4.0 International License

\begin{abstract}
This paper shows that the various rating calculation methods of business efficiency calculations are built according to an unified logic system. It provides an overview of the rich methodological background and presents a transparent system picture. The analysis shows that the general return requirement is the starting point for business efficiency calculation methods, pointing out that only those methods of calculation are suitable for measuring business efficiency which are logically consistent with the general return requirement. It shows also the essentials of the mixed profit categories and presents and interprets the method elements of business efficiency calculations, which can be used to construct various calculation formulas for different business matters. The uniform logic system of method elements may form a guiding thread when selecting and evaluating the correctness of the method used. The paper draws attention to the fact that a number of efficiency-computing conceptions obviously fail to comply with the general return requirement and consequently in such cases may also be preferred less efficient or even inefficient variants.
\end{abstract}

Keywords Business Efficiency, Return Requirement, Measurement of Business Efficiency, Ranking, Mixed Profit

\section{Introduction}

Efficiency is a commonly used phrase in both everyday lives and in scientific life. This paper focuses on the category of business efficiency. However, on the business activity literature, the phrase of efficiency arises in many contexts. The most common variants of this are as follows: organizational efficiency, process efficiency, production efficiency, productive efficiency, resource efficiency, operational efficiency, cost efficiency, energy efficiency, working capital management efficiency, machine efficiency, labor productivity and so on. These variants of efficiency can be considered as partial efficiencies, which analyze the efficiency according to different aspects. Their essential feature is that they can be improved at the expense of each other. There are also methods which use the multivariate efficiency indicators. The outcome of these methods depends on the indicators taken into account in the analysis. These are primarily used for ranking purposes (e.g. [1] [2] [3][4]). The literary incidence of the phrase of economic efficiency is also common. This category is mostly used by economic theory. In these cases efficiency analysis uses the categories and methods of economics (e.g. [5]). However, it is fairly common to use this term as a synonym for business efficiency (e.g. [6], [7],[8]).

Like other widely used business economics categories, business efficiency is used in different interpretations and according to different content. The fact that the concept of efficiency is unclarified appears in many cases. It is often mixed with the concept of labor productivity. In the middle of the last century Farrell [9] says: 'Indeed, for a long time it was considered adequate to measure the average productivity of labour, and to use this as a measure of efficiency.' (p.11) Starr [10] finds: 'Economists and industrial engineers are associated with productivity as a measure of efficiency.' (p.4) The exact definition of business efficiency is not known. Witzel [11] says: 'The theory is a simple one: efficient businesses survive while inefficient ones go to the wall.' (p.38) There is a common logical turning point, where researchers usually lead profitability back to efficiency (e.g. [11], [12]). According to Dellmann [13] economies follow the rational principle with the premise of bringing the greatest possible benefit to economic agents in the sense of their objective function, so profitability is considered as a multi-dimensional assessment criterion of business efficiency. There is a considerable agreement in the literature that the business efficiency is significantly related to profitability, but the concrete way of quantifying the relationship is not elaborated.

In the business efficiency literature there are two generally unfolding concepts: the first one is linked to the general orientation of management activities, and the other one to the evaluation of business matters. (Business matters 
include products, activities, projects, organizational units, strategic business units, and so on.)

\subsection{Business Efficiency Ratios}

When introducing the concept of business efficiency a frequent starting point is the maximization of an economic ratio. The economic content of these ratios are different. Probably the oldest among them is maximizing the output and input rates:

$$
\left[\frac{\text { OUTPUT }}{\text { INPUT }} \rightarrow \text { MAX }\right]
$$

Witzel [11] formulates this goal as follows: 'The ultimate aim is to increase output, to reduce inputs or (more usually) both, thereby improving profitability.' (p.39) According to some authors this concept of efficiency is not always ratio maximizing, but achieving an appropriate rate. Helmkamp [9] describes this as follows: 'Efficiency means maintaining a satisfactory relationship between a firm's resource inputs and its outputs of products or services.' (p.9) The output/input concept is at a high abstraction level. The practical interpretation and quantification of inputs and outputs raises a number of problems. The quantification problem was already indicated in the middle of the last century [9].

Business practice rarely uses the input and the output expressions. According to Schmalen [14], the minimum input and maximum output cannot be interpreted in practice. In his view the input means the expense and the output is the accomplishment expressed in monetary terms. Palenberg [15], mentions this issue as a principle of cost minimization and yield maximization

In many of the publications which are taking into account the practical viewpoints the following formula is applied:

$$
\frac{\text { RESULT }}{\text { EXPENSE }} \rightarrow \text { MAX }
$$

However, even this formula cannot exactly be quantified, since both result and expense of business matters are also quantifiable with multiple indicators. Consequently, a wide range of result and expense ratios can be compiled. Still, irrespective of whether the ratios or extreme values can or cannot be quantified, this formula is significant in two respects.

First, the principle behind the formula includes one of the main pursuits of sound management activities. This pursuit can be interpreted at all levels of business management. In each case related to activities and solution methods, it should be thoroughly examined whether there is a smaller expense may be possible for attaining the set goals, or how a given expense contributes to attaining the largest possible results. To maximize the result and expense ratio is a step in the right direction. Of course, this principle only is true if at the same time the pursuit has the most favorable impact on the profitability.
Secondly, as commonly known, a combination of several concrete variants of the result/expense ratio allows an analysis of the factors influencing the formation of business efficiency.

\subsection{The Concept of Evaluation}

According to the second approach, business efficiency is a rating which answers that question of whether the examined business matter is efficient, or is more efficient than the other variants. In general, the efficient rating means that the required effect is fulfilled [16]. This overall definition can also be applied for business point of view as the rating of efficiency. Over time, a rich methodological base has evolved for the determination of the business efficiency requirements and for examination methods with which their fulfillment can be determined. Zinti, in the foreword for Palenberg [15] says 'Efficiency is a powerful concept for decision making and ex post assessments of development interventions.'

According to the best of my knowledge, the literature does not address the overall issues of business efficiency analysis methodology. In the literature and in practice, efficiency analyses for different problems are referred to by different names, so their common features and content connections remain in the background. This is reflected also in Palenberg's [17] concept, when he says: 'Efficiency analysis from the business perspective is based on the analysis of discounted net cash flows and the resulting expressions that describe the internal efficiency of the business idea under scrutiny are, among others, the net present value (NPV) and the internal rate of return (IRR).' (p.24) As it can see, in the mentioned topics are included only a narrower part of the evaluation methods of investment projects and not a wide range of business matters.

The goal of selecting that variant which reaches the highest level of the efficiency requirements can also be interpreted as a way of result and expense ratio maximizing. However, this is not the case of a simple result and expense issue. Result and expense indicators must be in strict content harmony with each other. Unfortunately, there are some recommendations in the methodological storehouse of business efficiency that can provide grounds for confusion and some variants are highly misleading (Illés [17]).

\subsection{Purpose and Method}

This paper deals with the issue of business efficiency according to the evaluation concept, that is with the business efficiency requirements and the examination of whether these requirements are met and to what extent they are fulfilled. The main objectives are as follows:

a. To provide an overview of the rich methodological background and compile a transparent system picture. 
b. To show that the general return requirement is the starting point for business efficiency calculation methods.

c. To interpret the profit requirement and its content components as part of the fundamental return criterion.

d. To point out that only those methods of calculation are suitable for measuring business efficiency which are consistent with the general return requirement and can be deduced from its conceptual formula.

e. To show the essentials of the mixed profit categories as they are auxiliary of calculations.

f. To present and interpret the method elements of business efficiency calculations, which can be used to construct various calculation formulas for different business matters.

The main research methods are content analysis, method analysis, systematization, and the breakdown of methods into elements. Both logical and mathematical processes are used to provide proof.

The paper uses a business economics perspective in which business economics functions as an independent discipline and not one of the branches of microeconomics (Illés [17]). This approach interprets and manages the economic information and the database itself according to the real economic conditions, furthermore uses basically corporate terminology. It interprets the analyzed relationships on the model of the private-capital-owned company. For sake of simplification, the validity scope of the methodological investigations is limited to manufacturing companies.

Following the introduction, the structure of the paper is as follows.

- In line with principles of the economic theory, Section 2 works out the general return requirement which can serve as the basis for the elaboration of rating by efficiency. It points out that the opportunity cost interpreted on the capital can be structured and this structure can be transferred to the methodology basis of business efficiency.

- $\quad$ Section 3 outlines the main formulas on the basis of which the efficiency criterion can be measured also presents the principles of forming of the rates on the basis of which non-distorted ranking tools can be formed. It also points to the main reasons for the deviation in business efficiency and expediency rating.

- Section 4 presents that usage of mixed profit categories is necessary to determine the business efficiency in most business matters. In the business practice, the mixed profits are commonly used, but they often are hidden in the structure of the methodological recommendations. Getting to know their general principles can improve the professional preparedness of decision-makers and controllers.
- $\quad$ Section 5 presents the method elements of business efficiency analysis systematized by 6 main aspects. The knowledge of this system can be used when constructing the appropriate methodology and also when judging the correctness of a given method composition for a given purpose.

- Section 6 provides a brief review of deductible conclusions based on the study.

\section{The Return Requirement as a General Guiding Principle of Business Activity}

In principle, microeconomics defines the minimum criterion of return requirement correctly; however, it should be translated into the language of business economics. In this context, the most important problem is that microeconomics at its high abstraction level does not deal with the distinction between expenditure and cost, thus it does not deal with the occurring process of costs either. Furthermore, in microeconomics (as is well-known) the opportunity cost is listed as the usual cost, which in turn is included in the business economics context as a profit requirement.

\subsection{The Profit Requirement}

The processing of the controversial literature on profit requirement is not the subject matter of this paper. It applies a direct logical deduction from the microeconomics. The principle of the opportunity cost of microeconomics, as is well-known, is appropriate for the particular purpose of business efficiency calculations.

According to Samuelson and Nordhaus [18] 'The opportunity cost of a decision consists of the things that are given up by taking that particular decision rather than taking an alternative decision.' (p.469) The things given up can be very diverse. The business economics narrows down the examination of the circle of given up things to the obtainable profit possibility.

Another problem is that there are a lot of opportunity costs for each decision variant, even in a given economic content. The number of opportunity costs for one variant is as many as profitability themes lost with one of them being realized. Mapping these can take up to years. Therefore, business economics takes the average opportunity cost as the basis for determining the thresholds for decision making. If there is a threshold, then a single decision possibility can also be evaluated based on this. With this solution, the concept of return requirement for microeconomics and the business economics are - in principle - in line with each other.

Part of the category name is cost and this could be misleading from the practical point of view. Therefore, business economics uses the notion of profit requirement 
for this. (Finance names the return requirement according to the opportunity cost as a real cost, that is as an effective part of the cost.)

In this paper, the difference between the microeconomic and the practical cost content is called profit requirement. This item behaves as if it were a cost since it has to come back, but in practice, it is not a cost since there is no expenditure behind it.

If the profit requirement returns, the amount of it is shown as profit. However, profit is treated as a homogeneous amount at the company level; there is no difference between the profit according to profit requirement and the surplus profit resulting above it. In very lucrative companies, the profit is greater than the profit requirement, but companies where the profit requirement is only partially recovered also show a profit.

In the microeconomics the market value for the use of entrepreneur's own resources is called implicit cost. Samuelson and Nordhaus [18] say about this category: ‘... unpaid factors of production are often called implicit cost, which is a somewhat narrower concept than opportunity cost.' (p.470) The authors do not deal with the content difference between the two categories. However, this difference is very important in the business efficiency calculations. Namely, the difference between the opportunity cost and the implicit cost is the risk premium requirement. The risk premium requirement is a sort of profit requirement for the compensation of undertaking the market risk. Furthermore, the difference between the realized risk premium and the risk premium requirement may show as well the quality of the economic functioning of the company. If there is no chance of its return, it is not worth doing business. (So in this matter the business economics concept is also consistent with the microeconomic approach.)

The content approach of Ekelund and Tollison [19] is similar to the above: 'Implicit costs: the value of resources used in production for which no explicit payments are made...' (p.851)

According to the above, the basic characteristic of the use of own resources is that the company has no expenditure background, so it cannot be included in the costs and it is not even reasonable to call it a cost. If, however, the company had purchased that resource from another owner, the cost of use would appear among the usual costs. Consequently, the market price of using one's own resources should be included as a profit requirement among the return requirements. (This profit requirement component does not include a risk premium requirement.)

In the literature of business economics, the concept of the implicit cost occurs many times embarrassingly differently from the concept of microeconomic definition. For example, amortization is often referred to as an implicit cost as a result of the fact that the date of expenditure does not fall in the cost-accounting period. One of its typical examples can be found in the Managerial Economics book of Douglas [20]: '...the accountant charges an implicit cost against revenues each year in order to spread the explicit cost of the asset over the period during which the asset is being used in the production process.' (p.262)

The main content elements of the profit requirement are as follows:

- The estimated price for using equity. (Most of the profit in large manufacturing corporations is this type.)

- An allowance for using natural resources (land, mine) owned by the company.

- The labor market price (and contributions) of the work of entrepreneurs if it is not part of the cost.

- The risk premium (market premium) requirement.

The profit requirement, therefore, consists of two distinct featured components. One component is the price of using the entrepreneur's own resources, the other one is the risk premium requirement. In the manufacturing industry, the dominant element of own resource use is the equity. Here the issue of mining royalty and land rent usually does not arise. For big companies, the price or price difference of the owner's work may not, in principle, amount to a significant implicit cost.

The profit requirement estimation can be performed in an unstructured form or by summation of its content components. Business economics and its branches typically use the unstructured forms. (Finance usually estimates the profit requirement starting from its components. The two types of estimation are also a part of the different methodological basis of the two disciplines.)

\subsection{The Fundamental Return Criterion}

An enterprise that has not recovered from its total expenditure from the revenues over a longer period of time is considered, a priori, to be unsuccessful. Even the return of all expenses is not enough - the profit requirement must also be returned. So the basic principle of the return requirement can be formulated as follows:

\section{SALES REVENUE $\geq$ EXPENDITURES + PROFIT REQUIREMENTS}

The quantification of this formula to the whole company is complicated by the fact that expenditure includes also amounts that have been spent for buildings with a very long lifetime, or long-lived assets. For such a long period of time, sales revenues and expenditures for each year cannot be anticipated. This is basically why the long-term examination of the return requirement for the whole company is not typical in this form. However, for investment projects where annual revenue and expenditure lines can be mapped for the lifetime of the project, the above relationship can be quantified. In essence, the method of decision-making calculations for investment projects can be deduced from this theoretical context.

In the annual level examinations at the place of expenditure are the costs: 


\section{SALES REVENUE $\geq$ COSTS + PROFIT REQUIREMENTS}

These are called cross-sectional examinations. These examinations may target the whole company, enterprise units, projects, products, or activities to which can be identified revenues. After moving from the corporate level, the calculations become more and more complicated Revenue data are relatively unequivocal they can be well structured. However, estimates need to be used to quantify the costs and there is no solution that would be appropriate for all problems.

If there is probably a significant difference between the book value and the market value of fixed assets, on such an occasion it will be expedient to consider both values in quantifying the return requirements of the fixed assets.

\section{Classification and Expediency}

\subsection{Measurement}

According to the logical order of business efficiency calculations, first a decision must be made on whether it is worth dealing with the examined business matter at all. This means that first of all the business efficiency or inefficiency of the examined business matter needs to be known.

In order to determine whether a business matter is 'efficient' or 'inefficient', there is a need for rating criteria; which means that norms are needed in order to measure the business efficiency. First, boundary points and thresholds of business efficiency need to be set. The return requirement provides a basis to edit formulas for evaluation of the business matters. If the return requirement is achieved, the business matter under evaluation is efficient and if this requirement is not met the evaluated business matter is inefficient.

Business efficiency evaluations attempt to determine the conditions and circumstances under which the return requirement is met. Depending on the applied methodology, threshold types may also be different. Calculations can encompass an extremely wide range of methodologies depending on the nature of the problem and the possibilities of measuring the return requirements. If a business matter lacks any measurable revenues, the business efficiency requirement can be converted into an indirect return requirement formula. When using the indirect method, a variant is sought that creates the minimum return requirement with fulfillment of the required performance of the function.

There are very complicated formulas and calculation procedures. From these only those variants can only be considered acceptable which can be originated from the previously described fundamental return requirement formula. In what follows, the basic return requirement formula is used as a simplified variant, which is the general formula of cross-sectional analysis.
The surplus yield resulting from the difference between the sales revenue and the whole return requirement indicates that return requirements are met. A boundary point is the point where the surplus yield is zero. So not only can loss-making matters be inefficient. Even a profitable matter may be inefficient if the profit is less than the profit requirement. Based on the above considerations and simplifying the basic return criterion formula, the condition of business efficiency is formulated as follows (both sides of inequality are reduced by cost):

\section{PROFIT $\geq$ PROFIT REQUIREMENTS}

Logically, when both sides of the 'Profit $\geq$ Profit requirement' inequality are reduced by the price of using one's own resources the formula will be

\section{RISK PREMIUM $\geq$ RISK PREMIUM REQUIREMENTS}

The risk premium requirement differs from the actual realizable or realized risk premium. One is the norm and the other is the performance. (The literature is also confused in this subject.) Performance must at least reach the level of the norm. The higher the risk premium is, the more favorable the performance is.

Starting from the more detailed description of the basic return requirement formula, additional return requirement formulas can be created. For example the total return requirement for a given year is as follows:

SALES REVENUE $\geq$ VALUE OF USED UP RESOURCES + INTEREST PAYMENTS + PROFIT REQUIREMENT

where

PROFIT REQUIREMENT $=$ DEBT $\times$ REQUIRED RISK PREMIUM RATE + EQUITY $\times$ REQUIRED RATE OF RETURN.

(A loan also has a profit requirement. On the one hand, the accessible sales revenue does not depend on the invested money being the equity or loan. On the other hand, the primary risk holder of the loan is the company so the risk premium of product market has to be returned to the company for the loan also.)

By rearranging the detailed formula of the return requirement, another form can be obtained (proof: [Illés [21] and. [17]).

PROFIT + INTEREST PAYMENTS TOTAL CAPITAL

The yield rate on the left-hand side of this formula is the same as the well-known DuPont yield rate, which was developed by Donaldson Brown in 1914. Likewise, also the following formula can be deduced:

PROFIT - " PRICE" OF EQUITY USAGE TOTAL CAPITAL

Only the above two capital return rates can be derived from the basic return criterion formula. According to Vuko \& Ojvan [22], the corporate efficiency is approximated by return on assets, where ROA = OPERATING PROFIT/AVERAGE TOTAL ASSETS. This statement is 
acceptable because this business efficiency indicator is in principle the same as the well-known DuPont yield rate above. It is regrettable that the statement is not followed by any reference or conclusive explanation. The often calculated PROFIT/CAPITAL, PROFIT/ASSET, PROFIT/SALES REVENUE indicators are not suitable for characterizing corporate efficiency (the first and second indicators are distorted depending on the rate of debt and interest the third one is distorted by material necessity and rotational speed). However in the literature in connection with the concept of business efficiency, misleading suggestions can also be found for the measure of business efficiency. For example, Stepanek [7] considers the return on equity $(R O E=N E T$ PROFIT $/ E Q U I T Y)$ indicator as the most appropriate indicator to measure efficiency. Wassmuth [23] suggests to this purpose the rate of INCOME /COST. According to Mouzas [12], PROFIT / SALES REVENUE rate should be used to this. (This latter indicator is often used in practice as well.) A theoretical and methodological analysis is missing in all of the mentioned cases.

In economic areas where the capital need is relatively low, the capital profitability is not suitable for efficiency measurement [24].

Below the corporate level, more sophisticated transformations are needed to determine the efficiency threshold. These thresholds as norms are the absolute categories; basically, the tools used for selection (of whether the matter is efficient or not).

In management practices, the most important information for all business matters is whether all costs and capital yield requirements associated with them are reimbursed. This is not the only information, but is the most fundamental. The evaluation of business efficiency does not mean the decision itself. However, it provides one of the most important types of information for decision making. The motivation of professionals plays a significant role both in the process of information gathering and in the decision-making. (Detailed explanation of this problem: Illés [21])

\subsection{Ranking and Rating Scale}

As a second step, it must be taken into consideration that there might be several decision variants that exceed the return requirements. Starting from this, the variant with highest surplus yield needs to be selected. In order to do this, the examined variants must be ranked by business efficiency. This ranking - if the index used for ranking is based on a good principle - shows which examined products, activities or action variants are the most favorable. (For example, the net present value and the CONTRIBUTION MARGIN/PRICE can result in a misleading hierarchy. For details see [17]). The ranking is a relative category; the position of an examined variant in the ranking list depends exclusively on the parameters of the other variants in the list. A business matter will be placed in the first position of the list if it is compared with worse variants than itself. The same business matter will be placed in the last position if it is compared with better variants. Since in addition to the general cases the exclusively efficient and exclusively inefficient products, actions and activities can also be ranked, it can be concluded that a ranking list cannot under any circumstances substitute for measurement by norms.

The ranking generating indicators can generally be developed according to some kind of ratio. The only exception to this may be when the values in the denominator are the same in all examined variants. Ensuring the content harmonization of the numerator and denominator is a very important requirement. If the ranking generating indicator is based on a faulty concept the ranking provides misleading information, just as it happens in cases when setting of the return requirement formula is based on a faulty principle. (By taking the pre-selection based on business efficiency, any faulty effect of the ranking generating indicator - which often occurs - can be reduced somewhat.) Among the recommendations for product ranking according to contribution margin ratios is given the largest weight. In this case, as described above, the classical contribution margin is in the numerator and the price is in the denominator. With regard to its purpose, there is a significant distortion effect both in the numerator and in the denominator (Illés [21] and [17]).

The methodological storehouse of business efficiency calculations contains also a rating scale. This method is used when the business efficiency of many variants should be reviewed. When a rating scale is applied in this context, the products or activities first are ranked by their business efficiency criteria and then they are classified into qualifying categories. The usefulness of this solution depends on whether concise and clear classification criteria for business efficiency have been developed. As for the rating scale, the literature has a rather poor methodological background. In the available literature, the rating scale methodology is developed only for products. However, the majority of these methods are either debatable or misleading [17].

\subsection{Business Efficiency and Expediency}

The criterion of expediency is interpreted in a slightly different way than business efficiency. Expedient means advantageous in one or another sense. Aspects of business efficiency and expediency may differ. Not only efficient business matters are considered expedient, and vice versa. Basic cases:
EFFICIENT
EFFICIENT
INEFFICIENT
INEFFICIENT

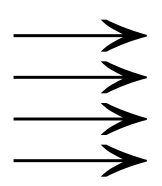
EXPEDIENT
INEXPEDIENT
EXPEDIENT
INEXPEDIENT

Of the above four cases, the two cases in the middle are 
worth considering: Why should something be qualified as inexpedient if this something is efficient? And vice versa: Why should something be qualified as expedient if it is inefficient?

From a wide range of possibilities of efficient business matters, it is usually advised to realize those variants that are generating the highest surplus yield rate above the required rate. The first variant is efficient and expedient at the same time. However many business matters which are considered to be efficient may count as inexpedient due to limited resources. As a result, the execution of an obviously efficient matter becomes inexpedient if there is a better variant. Surprisingly, according to a given method, the execution of inefficient business matters may frequently be classified to be expedient. Most of them can be formed by the following relationships.

- The limitations of the given method do not allow a complete mapping of business efficiency relationships. For example, a snapshot (cross-sectional analysis) taken of business efficiency indicates that the given matter fails to fulfill the return requirements during the examined year and is considered inefficient. However, it may be regarded as expedient if all (cumulative) return requirements are met in the future. In such cases, it frequently happens that using an appropriate method allows the longer-term business efficiency to be detected. (That is, the matter is efficient according to another method.) At the same time, in many cases, it may also be interesting to learn to what extent the return requirement is met in a given year. (The production of a strategic product must not be stopped during the first years of its manufacturing even if the snapshots show that the product is inefficient. But it is also important to know what level of business efficiency is fulfilled in a particular year.) There may also be business matters whose diversified effects and complex relationships do not allow precisely mapping of the return on the return requirements, but they are efficient. The typical example is when various types of expenditures are spent for the good reputation of a company.

- The examined business matter is inefficient if it itself is measured separately; however, its overall impact has a relative loss-reduction effect, and therefore it may be expedient. This mostly means that at a lower measurement level a business matter labeled inefficient also may be advantageous if it shows a loss-reducing effect at a higher level measurement. The range of such possibilities is wide. At companies with high profitability, there may also be a number of less successful business matters through which profitability measured at company level can be further improved by using the 'save what can be saved' principle. The most typical example is as follows: the product which not meet the return requirement, but whose price is above the marginal cost that is desirable to produce if there is no better solution to the utilization of the given capacity.

- Activities and actions that are definitely inefficient due to distortions in the corporate interest systems may become expedient. It may occur that a less efficient or a really inefficient variant best serves the decision-makers' interests. If the control serving employers' interests is not strict or sophisticated enough, decision-makers are more likely to choose the inefficient variant if it is better according to their interests (for example convenience, corruption, and so on). Almost every company has some experience to illustrate this sort of behavior.

\subsection{Firm's Own Average as a Distorted Norm}

Firm's own average as a norm is applied in corporate practice and is also recommended in the literature. This mostly means that a company considers its own profitability level as a norm of business efficiency for making further decisions. If this corporate average is higher than the sector average, the profit requirement rate demands a higher rate of capital yield requirement than the usually required rate of return. The conscious application of this allows competitiveness to be maintained at the desired level. In reverse cases, that is, when there is a low level of corporate profitability, the company takes on a lower level norm of profitability for each case of a business matter than the usually required rate of return. Mostly, this specific norm is applied only from habit or as an effect of some faulty practical recommendations. This practice may be dangerous for weaker companies. Of course, the weaker company also has an interest in choosing the best variant. There is a problem if the best variant does not meet the right return criterion.

\section{Mixed Profit Categories}

To make the business efficiency calculations both cost (or expenditure) data and return data should be prepared with content tailored to the nature of the problem.

In a given year the profit sum of products, activities, organizational units, strategic business units, and projects cannot be calculated directly due to the complex nature of cost relationships. However, there is a great need for such information. In this respect, two principles can be used for the treatment methods of costs. With the first principle, all the costs incurred in a given year should be divided into the different business matters. The exact causal relationship cannot be explored for a significant part of the costs; therefore, there may be serious distortions during the subdivision process. According to the second principle, only those costs are to be divided where the resource consumption structure is clear. Nowadays, the latter is the 
commonly used solution for business efficiency analysis. However, when applying the latter principle, the outcome indicator includes not only the profit but also the recovery of those cost elements which were not taken into account among the deductible items. These outcome indicators can be named mixed profits. (As far as I know, this category does not appear in the literature. Its introduction is required for the comprehensive examination of business efficiency calculation methods.) Depending on what circle of costs can be taken into consideration at a given matter, the mixed profit indicators contain different combinations of profit and costs. It is very important to know the ingredients of the given mixed profit in order to make further steps of the return process analysis.

The available literary sources do not deal with a comprehensive overview of the system of the mixed profit indicators. The literature only addresses forms and categories related to specific topics from a methodological point of view in an isolated context. In order to improve the problem-solving ability of managers, it is fundamental to gain an overview: although the analyzing methods of business efficiency are different and their correct application depends on the types of the business matter and the analytical goal, all of these methods are based on the unitary principle of the return requirement. (At least, they need to be built on this unitary principle.) One of the pillars of application of the unitary principle is the category of mixed profit built up according to different elements.

The range of mixed profit indicators is wide. The majority of these indicators are built on the following logic principle:
SALES REVENUE (OR PRICE)

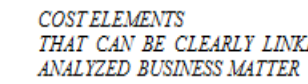

According to the above, the content structure of the mixed profit is determined by the difference between revenue and the topic-specific cost elements. So the two main constituents of this difference are the profit and those cost elements which are not possible to link to the analyzed matter.

$$
\begin{aligned}
& \text { MLXED } \\
& \text { PROFIT }
\end{aligned}=\text { PROFIT }+\quad \begin{aligned}
& \text { COSTELEMENTS } \\
& \text { THATCANNOT BE LINKED TOTHE }
\end{aligned}
$$

Examining the structure of mixed profit, it may seem that the mixed profit can be calculated by summation. However, this is absolutely wrong because in this case exactly the essence would be lost. The use of mixed profit has become necessary because in the given cases the cost elements cannot be separated from profit without violating content relationships. For the sake of managing relationships, it is essential to have a clear understanding of the economic content of the components.

Often special terms are used to indicate the particular economic content of mixed profit. These categories must be used cautiously because terminological strictness in this field is not typical. It may occur that several terms are used to express the same economic content. It may also happen that the same denomination is used to express different economic contents. In most cases, the meaning of category becomes clear from the given context. The main types of mixed profit and their meanings are summarized in table 1.

Table 1. Main types of mixed profit

\begin{tabular}{|l|l|l|l|}
\hline \multicolumn{1}{|c|}{ TOPIC AREA } & \multicolumn{1}{|c|}{ NAME } & \multicolumn{1}{c|}{ ECONOMIC CONTENT } & \multicolumn{1}{c|}{ TREATED PROBLEM } \\
\hline $\begin{array}{l}\text { INVESTMENT } \\
\text { PROJECTS }\end{array}$ & $\begin{array}{l}\text { Yield; } \\
\text { Gross yield; } \\
\text { Cash flow; } \\
\text { Gross cash flow } \\
\text { EBITDA }\end{array}$ & $\begin{array}{l}\text { Amortization and the annual amount of } \\
\text { the profit; or profit and the face value } \\
\text { return part of the investment amount } \\
\text { related to the investment project. }\end{array}$ & $\begin{array}{l}\text { The uncertainty of time display of } \\
\text { amortization as a cost reckoning. }\end{array}$ \\
\hline $\begin{array}{l}\text { TECHNICAL } \\
\text { DEVELOPMENT }\end{array}$ & Not created & $\begin{array}{l}\text { The annual amount of the profits of the } \\
\text { technical development and the recovery } \\
\text { of research, development and } \\
\text { introduction expenditure. }\end{array}$ & $\begin{array}{l}\text { The lack of knowledge of the } \\
\text { temporal evolution of the payback of } \\
\text { expenditure for research, } \\
\text { development, and introduction. }\end{array}$ \\
\hline $\begin{array}{l}\text { FACTORIES, PLANTS, } \\
\text { MANUFACTURING } \\
\text { UNITS }\end{array}$ & Not created & $\begin{array}{l}\text { The entity's profit and a part of the } \\
\text { corporate (and factory) overhead cost and } \\
\text { profit requirements. }\end{array}$ & $\begin{array}{l}\text { Uncertainties of allocation of } \\
\text { corporate (and factory) overhead costs } \\
\text { and profit requirements. }\end{array}$ \\
\hline $\begin{array}{l}\text { PRODUCTS } \\
\text { (ACTIVITIES) }\end{array}$ & $\begin{array}{l}\text { Contribution margin; } \\
\text { Product's gross } \\
\text { operating margin }\end{array}$ & $\begin{array}{l}\text { Several variants are used and can be } \\
\text { constructed as well. }\end{array}$ & $\begin{array}{l}\text { The uncertainties of causal } \\
\text { relationships for the cost and profit } \\
\text { requirement of products. }\end{array}$ \\
\hline PRODUCTION VOLUME & Gross profit* & The amount of fixed costs and profit. & $\begin{array}{l}\text { The independence of fixed costs from } \\
\text { the production volume. }\end{array}$ \\
\hline
\end{tabular}


In business literature, the major interpretations of gross profit are as follows:

- In break-even analysis, the gross profit is the difference between sales revenue and all of the proportional costs; this interpretation is used in this paper.

- In accounting, the gross profit is the difference between sales revenues and all of the direct costs.

- In the master budget, the gross profit is the difference between sales revenues and all of the manufacturing costs.

\subsection{Yield of Investment Projects}

The determination of the profits of investment projects is made difficult by the fact that the amortization cost may be freely adjustable within certain limits. The project economic evaluation methods resolve this problem in a very elegant manner. These methods manage amortization costs as a face value return together with profit. The calculation is resolved in such a way that only operating costs are deducted from the sales revenue. The literature uses different terms for the received difference. In business economics this difference usually was called 'yield' in the middle of the last century. Since the mid-1980s, business economics uses also the term 'cash flow', which was taken over from finance. The term 'gross cash flow' is also frequently used, since the profit component of this has profit tax content. The usage of categories is far from being considered consistent. In order to avoid content uncertainties, hereinafter the term 'yield' is used to represent the mixed profit containing the sum of pretax profit and the annual amount of amortization or pretax profit and the face value return a part of investment amount. .

Nowadays the term yield is related to different economic actions and has a large number of economic contents. However, in investment project evaluation terminology, the term yield does not generally have different contents.

The methodology of investment project evaluation calculates the return requirement according to the following principle: All the yields generated during the duration of the project must cover both the nominal sum of investment and the profit requirements charged according to the required rate of return. The profit requirement is applied to the sum of yearly tied-up capital.

When examining the business efficiency of a former investment project, it frequently cannot be cleaned project yield from corporate governance costs. At this point, the difference between the sales revenue and the operating cost leads to a special mixed profit category comprising the amortization (the return of an investment part), the project-related corporate governance costs and the profits. With the latter problem, the literature of business economics does not deal with merit. From the point of view of system displacement method, there is no need to examine the cost of corporate governance. Because they mostly are fixed costs, it may be generally assumed that the new project will not create any surplus in corporate overhead costs. (Cannon [25] draws the attention to the fact that the distribution of overhead costs may distort the evaluation of investments.)

\subsection{Mixed Profit Category of Technical Developments}

Several solutions can be used in accounting for expenditures of technical development. Regardless of this, the efficiency analysis approaches this question from the economic content side. The methodology principle used below also ignores the variability of accounting.

The principle of examination assumes that the mixed profit generated by the technical development must cover the expenditures on research, development, and deployment, and furthermore the profit requirement. The method considers the above-mentioned expenditures as investments, so the profit requirement is concerned to the not-yet recovered technical development expenditures as the yearly tied-up capital. No special name for this variant of mixed profit has been created. The fulfillment of the return requirement can be mapped on the basis of technical development yields.

This method is very similar to investment project evaluation methods both in form and content. However, the calculation of the generated mixed profit is extremely complex and is completely impossible in some cases. For example, the technical development may contribute considerably to maintaining the demand and the income at the same level. In these cases it is difficult to quantify how much the market demand for a specific product would have decreased if the product development had not been realized.

\subsection{Mixed Profit Category of Enterprise Units and Products}

Business efficiency evaluations encompassing one year and the evaluations within one year belong to the category of cross-sectional analyses. The return requirements and returns are calculated for a whole year or within a year and not for the whole lifespan. The majority of cross-sectional analyses are aimed at evaluating the business efficiency of enterprise units or products. The supplementary cross-sectional analysis of the economic viability of investment projects may also be essential.

The lower the corporate measuring level at which the efficiency evaluation is performed, the wider the circle of the common return requirement is that cannot be directly related to the analyzed business matter according to the causal relationship. The hierarchy of measuring levels within a company is as follows:

- economically separable corporate units (there may be several measuring levels within this); 
- $\quad$ products and activities (in the case of semi-finished products with market prices there is a further measuring level);

- technological systems and procedures;

- machines and pieces of equipment.

At the level of the factory units, only the corporate overhead costs and the related profit requirements occur as return requirement which is as non-divisible for factories on the causal basis. At the plant level, beyond the corporate overhead costs and the related profit requirements, the factory level overhead and the relevant profit requirements are also part of the jointly reimbursable items. At the level of products and activities, above and beyond the total overhead costs of the participating plants (mostly more than one plant) and the related profit requirements, the return requirements of unused capacities also increase the number of items to be jointly reimbursed.

Since there is no generally known principle basis for distribution of these joint return requirements, the topic related sums of these cannot be quantified.

The mixed profit applied for corporate units and products is also based on the principle that those costs that cannot directly relate to the products, activities or examined business units must not be distributed among them, because this distribution will result in distorted cost information from the decision aspect. However, the expression of "directly related to' is not clearly determined. For example, in the case of products, this expression can be interpreted from two aspects: this can be the actual production process or a reproduction aspect.

The difference between the price and the partial cost or the partial return requirement is termed contribution margin or product's gross operating margin. The content of the partial return requirement which is deducted from the price depends on the type of decision; consequently, the economic content of the resulting product contribution margin will not be uniform.

The mixed profits of economically independent units also have different economic contents. Their contents depend on the level of corporate hierarchy (plant, factory unit, etc.).

\section{Method Elements of Business Efficiency Analysis}

The efficiency of a business matter can be examined from different aspects. Right at the beginning of the analysis, it is essential to make clear the nature of the examined business matter and to determine those conditions under which the yield effects will be investigated.

The scope of method elements of business efficiency analysis contains one-dimensional methodological solutions to assemble (to put together) the most appropriate method for evaluating a given business matter. Furthermore, based on a systematic review of the method elements, it is possible to ascertain whether all the constituent elements of a given methodology to be used are consistent with the nature of the business matter being examined and the purpose of the examination. As a matter of fact, several methods can simultaneously be used for evaluating a particular business matter, depending on the different aspects and examination purposes.

Because of this, the applicable methods to evaluate business efficiency can be extremely diverse depending on the purpose of the analysis and the nature of the problem being examined. The good knowledge of the method elements can be used not only when constructing the appropriate methodology but also when judging the correctness of a given method composition for a given purpose. In the latter case, the analysis can be done by breaking up the given methodology into elements. Figure 1 gives a systemized overview of the most important method elements.

As Figure 1 shows, the system of the method elements of business efficiency analysis is based on six type-forming criteria. The elements belonging to the different type-forming criteria are largely independent of each other, that is, they can be combined relatively freely. This partial independence means that in some cases an application of a particular method element brings with it another element application. This peculiarity will be detailed when reviewing the method elements.

Usually, not all six methodological features listed characterize a given calculation proceeding. Instead, a given proceeding is generally characterized by the most important method element (for example whether the method is static or dynamic).

The analysis has some limitations, as not all spillover effects of decisions can be included in the calculations. Because of this, it is advisable to attach the most important relationships that are left out of the basic calculation in the form of a textual analysis. 

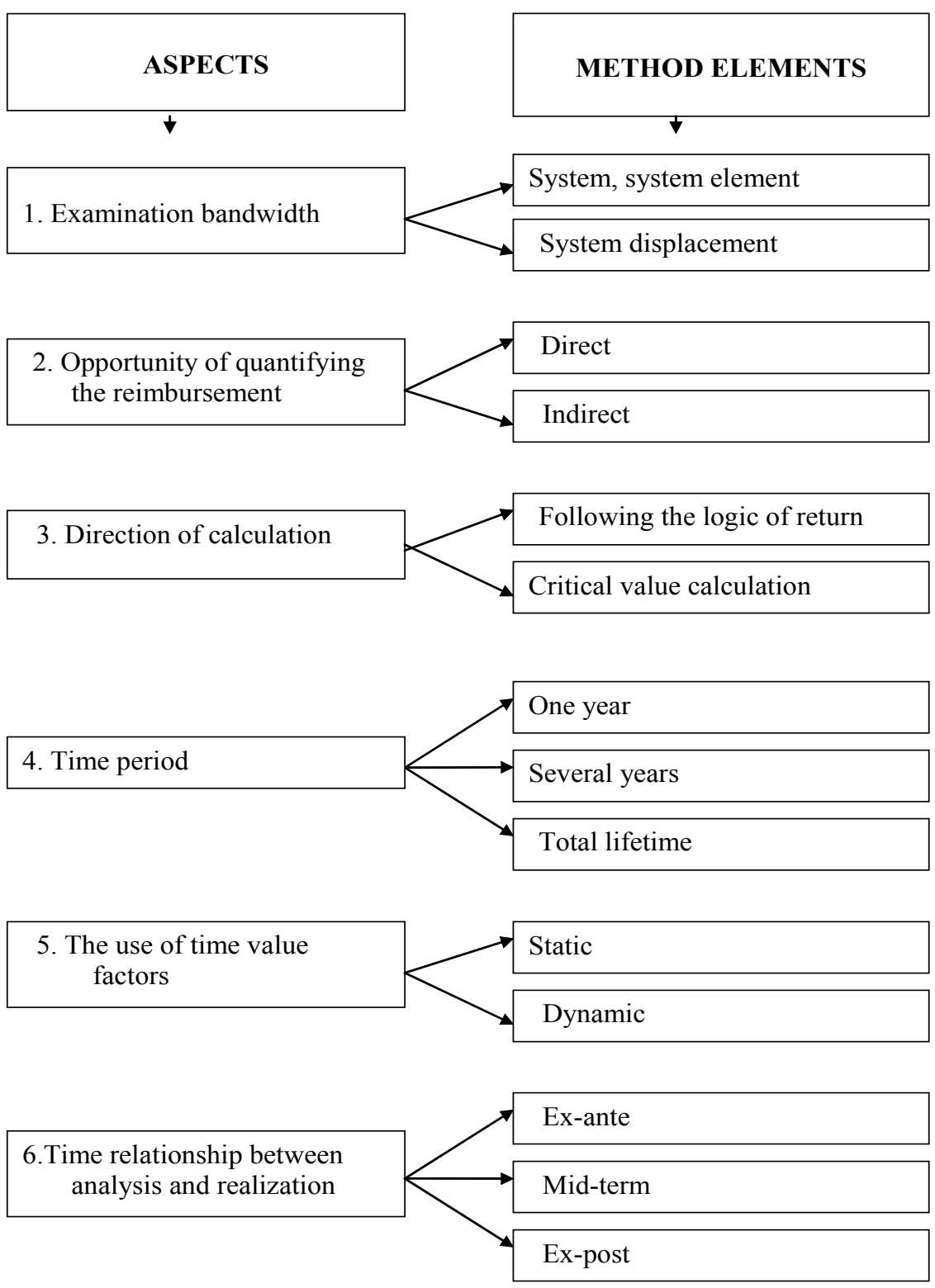

Source: [26.]

Figure 1. Major method elements of business efficiency analysis

\subsection{The Bandwidth of the Examination}

The examination may target a whole system and one of its elements or system displacement. The system and the system element examination take into consideration the complexities of a business matter. The system displacement examination follows the logic of marginal analysis (the principle of comparison of surplus revenue and surplus return requirement).

The business efficiency evaluation of the whole system can lead to the assessment of the company level economic activity. This evaluation is relatively easy to do on an annual level database (however, the various manipulation possibilities of accounting information should not be forgotten). The minimum criterion is known: the total sales revenue must cover the total costs and the profit requirement. The literature usually does not handle the calculation of the business efficiency for a whole company as part of the methodology of business efficiency analysis.

According to the above, the quantification of the pure profit content is problematic for system elements that can be examined individually as a result of the relative separability. The boundary points of particular system elements efficiency can be mapped with only a great enough uncertainty. Different categories of mixed profit provide significant help in examining the fulfillment of the return requirement. 
The system displacements contain different types of relationships; therefore, their examination requires a completely different approach. The displacement may mean both to expand and to narrow the system or system element. If the system is expanded, the surplus return requirement needed for shifting the system must be compared with the surplus revenue. Consequently, in such cases, the business efficiency of the system displacement can usually be quantified with a fair degree of clarity. However, there are cases where the compilation of necessary information may also be very complicated. For example, when the company eliminates a narrow production cross-section through a smaller investment, then more products can be processed across all production cross-sections. In order to quantify additional revenue and additional return requirements, it is also necessary to explore what surplus products could be produced and what possible surplus quantities could be according to the individual product variants. In such cases, several activity variants can be examined.

Thus, it frequently occurs that one of the system elements is inefficient according to its complex relationships, but can be considered efficient if it is looked at as a displacement in an already functioning system. If any of the system elements is wanted to be terminate it is not sufficient to know that this element is inefficient. It is expedient to analyze what potential impacts can occur when examining it as a system displacement. For example, a company intends to sell one of the plant units which is operating inefficiently. This plant unit reimburses all of the related costs. The selling is only an expedient solution if the selling price is no less than the present value of all reimbursable amortization costs. In the case of a lower selling price, further functioning is the better solution. (This means that further operation of the plant unit is efficient if this is considered to be a system displacement.)

\subsection{The Opportunity of Quantifying the Reimbursement}

From the aspect of quantifying the return, the method of business efficiency examination can be direct or indirect. In business matters, where profit implications can be clearly interpreted the main question is the following: whether the resulting profits are sufficient to meet the profit requirements. Calculation methods that examine the fulfillment of the profit requirements are called direct methods.

There are business matters where the profit effects are not quantifiable even with a rough estimate. In such cases, detour roads must be chosen. These sorts of solutions are called indirect methods. The detour road usually leads to evaluation using comparative analysis of the return requirements of decision variants. The starting point of this method is that a given task (function) is expedient to carry out with a variant of the lowest possible return requirement.
According to market price forming trends, in prices, the average expenses and profit requirements are reimbursed. If a company performs some functions or activities at a lower return requirement (cost plus profit requirement) than the average, then these activities and solutions can be regarded as business efficient. (In such cases, a larger amount will be reimbursed than the return requirement.) If the company implements the given task with a higher than average return requirement, according to the above argument, the applied variant is considered to be inefficient. The other question is whether if it works, is it advisable to replace it?

If indirect methods are used for analysis, the business efficiency of the examined variant can be judged to be significantly less clear since there is no accurate information about the average return requirement. For instance, if a company examines what heating systems would be economical to install in order to ensure the proper temperature at workplaces it must measure the cost of the various energy sources and explore the heat utilization of applicable heaters, equipment prices, operating life, etc. The method can only help to answer which is the cheapest or the most expensive of the examined variants. However, it is not possible to search for and analyze all of the variants of a heating system.

The available literature dealing with indirect methods of business efficiency analysis is not as rich as the literature of direct methods, even though the use of indirect methods is much more frequent than the use of direct methods. For example, big and complicated projects with measurable yield effects have many project units. These units usually do not have measurable profit yields so the variants to be realized must be selected using indirect methods. Similarly to project units, indirect methods apply for each machine of the machine line, as well as for cleaning machines, heating and lighting equipment, and so on.

In the application of indirect methods of business efficiency examinations, usually ranking is a good solution because there is no clear measuring opportunity.

\subsection{Direction of Calculation}

According to the direction of calculation the business efficiency examination methods are as follows: the straight-line method, which following the logic of return, and the critical value calculation. The direction is following the logic of return when its main question is whether the resulting yield is sufficient to meet the return requirement. The direction is straightforward in the case also when the question is which variant is cheaper.

If one data contains a high degree of uncertainty for an examined business matter, the calculation procedure should exclude this indicator from the range of indicators with a relatively high degree of data accuracy. After that, the critical value of this missing data is to be calculated. Critical value calculation as business efficiency analysis 
means the computation of values where the business efficiency of a matter turns around. The critical value itself - depending on the content - can mean the following. The examined business matter becomes not efficient if, compared to the critical value,

- the profit is lower

- the needed sum for the investment project is higher

- the yield is lower

- the selling price is lower

- the operating cost is higher

- the need for labor is greater, etc.

Based on the comparison of the critical value and the known uncertain data, the decision can only be reassuring if the expected value of the uncertain data is significantly more favorable than the critical value.

Critical value calculation can be associated with both direct and indirect methods. If the computation is combined with indirect methods, the critical value is linked to the sum of the return requirement of another business matter. The critical value is that point where the change of ranking will occur. From this point, the return requirements for the other variant would be lower. (Using an indirect method and critical value method together will happen, for example, when quantifying the maximum price that can be paid for a particular industrial boiler in order not to exceed the yearly average return requirement compared to another boiler, taking into account lifetime and operating costs.)

\subsection{The Time Period Taken into Account}

The time period encompassed by calculations may be one year, several years or the whole lifetime of the analyzed business matter. In this case of cross-sectional analysis, the purpose of the examination is to know whether the business matter in question is efficient in a given year. A repeatedly carried out cross-sectional analysis can provide information about the business efficiency for a multi-annual time period. The business efficiency examination of products most frequently is carried out as cross-sectional analysis.

For certain system elements (products, product variants, fixed assets, technological processes), it should also be examined whether the return requirement is fulfilled during the full lifetime. Investment projects tend to carry the greatest weight among business efficiency examinations covering the whole lifetime.

\subsection{The Use of Time Value Factors}

One of the important features of the business efficiency calculation procedure is whether a time value factor is used There are about 8 to 12 kinds of relevant time value factors in the literature; usually three of them are used in business economics: future value factor, discount factor and the capital recovery factor (loan repayment factor). From the point of view using time value factors, the method can be static or dynamic.

The main characteristic of static calculations is that their methods do not include time value factors, and do not apply the principle of compound interest. The cross-sectional examinations discussed above simultaneously are also static ones. In this respect, there is a deterministic relationship between the method elements. Static methods usually take the economic outcomes and return requirements of a given year or a selected year into the account for analyzing business efficiency. An important requirement is that the results of the calculations must be interpreted accordingly. Generally, on their own, they are not suitable for prognostic purposes. The result of static calculations for a given year cannot be used for a time period of more than that year, and may only be extrapolated in very exceptional cases when specific conditions are met.

The deterministic relationship between the method elements is not valid in reverse. Namely, static methods can be used not only within the framework of cross-sectional examinations. If the special conditions are met, the static method can also be used as a basic method for a total lifetime calculation as well. The result will be correct, as proven in [21].

Dynamic methods are characterized by the use of time value factors. These methods are used to qualify business matters whose implementation and utilization process takes several years. The use of such calculations is much more complicated from a methodological point of view than the static methods. Here, the yearly variable economic results and expenditures of several years, together with the economic consequences of the passing time, are synthesized together in one indicator. In the case of the combination of indirect and dynamic methods the expenditures and the time data associated with the different solution options of the given function form the main data of the examination. Accordingly, the static or dynamic character of an examination method is independent of whether its database is concerned to a past, a present or a future period.

\subsection{The Time Relationship between Analysis and Realization}

Business efficiency analyses can be done before the decision is made, during decision making, and after implementation. Most commonly the preliminary so-called ex-ante examinations are applied. In such cases, the calculations are expanded with different forecasting methods and risk management methods. The calculation according to more data variants is also characteristic.

Intermediate examinations are based partly on factual figures and partly on plans and forecasts. The lifetime of the investment projects is relatively long. During this, environmental conditions change, knowledge is developing. The importance of the intermediate examinations follows that through the continuous 
observation and with the newest knowledge the business efficiency can be further improved, or can reduce the risk of economic loss.

Ex-post evaluation helps to enhance cognition of real processes and to strengthen the process of corporate learning. This type of evaluation is built on factual data. Compatibility gaps in the corporate information system may constitute a serious obstacle to ex-post evaluations.

\section{Conclusions}

Business efficiency is a category connected to one of the main goals of the business which is the profit. Comprehensive literature processing of this category is not known. The basic principles of its examination methods are not elaborated. The literature on business efficiency is fragmented. In this topic, there is no elaborated comprehensive knowledge circle but rather there are only smaller and larger methodological islands. The methodological recommendations are recipe-like: the questions of 'how' are in focus, the in-depth exploration of 'why that and why so' questions are missing. The correct methodology can be compiled according to the uniform principles of the complex business system. Methods proposed by this paper are based on economic theory. Starting from the microeconomic principles, the paper points out that a company or a business matter can only be considered business efficient if it fulfills the requirement of recovering the used resources and the yield requirement associated with the capital tied up. When a business efficiency ranking formation indicator is constructed it is also necessary the using of this principle. Several misleading methods are included in the literature recommendations. The analytical presentation and explanation of the contexts and economic content of the methods can contribute to filtering out of defective solutions. Furthermore, the knowledge of the background of the methods and their contexts can contribute to improving the quality of their practical application.

\section{REFERENCES}

[1] Daraio, C. \& Simar, L. Advanced Robust and Nonparametric Methods in Efficiency Analysis. Methodology and Applications. Springer Science \& Business Media, New York. (2007)

[2] Koty, L. A gazdasági hatékonyság számítása DEA lineáris programmal (Calculation of Economic Efficiency with DEA Linear Program). Statisztikai Szemle, Vol 75, No. 6. pp.515-524. (1997)

[3] Bronn, C. \& Brønn, P. C. Reputation and Organizational Efficiency: A Data Envelopment Analysis Study. Corporate Reputation Review. Vol. 8, No. 1, pp. 45-58 (2005)
[4] Wilson, P. W. FEAR: A Software Package for Frontier Efficiency Analysis with R Socio-Economic Planning Sciences. Vol. 42, No 4, pp. 247-254 (2008)

[5] Arrow, K. J., Chenery, H. B., Minhas, B. S. \& Solow, R. M. Capital-Labor Substitution and Economic Efficiency. The Review of Economics and Statistics. Vol. 43, No. 3. pp. 225-250 (1961)

[6] Wassmuth, R. \& Beuing, R Model Calculations on the Economic Efficiency of Sheep Production. Livestock Production Science, 1; pp. 67-75. (1974)

[7] Stepanek, J. Management of Economic Efficiency in Small and Medium-Sized Enterprises. Ad Alta, Journal of Interdisciplinary Research. Vol. 3, No. 1, .pp. 109-113.(2013)

[8] Geamanu, M. Economic Efficiency and Profitability. Studia Universitatis "Vasile Goldis" Arad Seria StiinNe Economice Anul 21/2011 Partea a II-a. pp. 116-119. Arad. ( 2011)

[9] Farrell, M. J. The Measurement of Productive Efficiency. Journal of the Royal Statistical Society. Series A (General), Vol. 120, No. 3 pp. 253-290. (1957)

[10] Starr, M. K. Managing Production and Operations. Prentice-Hall, Englewood Cliffs, New Jersey. (1989)

[11] Witzel, M. A short history of efficiency. Business Strategy Review. 13 (4), pp. 38-47. (2002)

[12] Mouzas, S. Efficiency versus effectiveness in business networks. Journal of Business Research 59 (2006) 1124-1132. (2006)

[13] Dellmann, K.. \& Pedell, K. L. (Hrsg.) Controlling von Produktivität, Wirtschaftlichkeit und Ergebnis. (Controlling of productivity, business efficiency and earnings.) Schäffer-Poeschel Verlag Stuttgart. (1994)

[14] Schmalen, H. Általános üzleti gazdaságtan. (Universal Business Economics) Axel-Springer Budapest Kiadó. (2002)

[15] Palenberg, M. Tools and Methods for Evaluating the Efficiency of Development Interventions. Evaluation Working Papers. Bonn: Bundesministerium für wirtschaftliche Zusammenarbeit und Entwicklung. (2011)

[16] Magyar Larousse Enciklopédia (Hungarian Larousse Encyclopedia) Akadémiai Kiadó, Budapest. (1992)

[17] Illés, M. Practical Usability Problems in Business Economics. Advances in Economics and Business Vol. 4, (11.) pp. 617-633. (2016)

[18] Samuelson, P. A. \& Nordhaus, W. D. Economics. Twelfth Edition. McGraw-Hill Book Company, New York. (1985)

[19] Ekelund, R. B. \& Tollison, R. D. Economics. Little, Brown and Company. (1986)

[20] Douglas, E. J. Managerial Economics. Theory, Practice and Problems. Prentice-Hall, Inc. Englewood Cliffs, New Jersey. (1983)

[21] Illés, M. Vezetői gazdaságtan (Managerial Economics) Kossuth Könyvkiadó, Budapest.(2002)

[22] Vuko, T. \& Ojvan, I. Controllling and Busieness Efficiency. Croatian Operational Research Review (CRORR), Vol. 4, 
pp. 44-52. ( 2013)

[23] Wassmuth, R. \& Beuing, R Model Calculations on the Economic Efficiency of Sheep Production. Livestock Production Science, 1; 67-75. (1974)

[24] Hedija, V., Fiala, R. \& Kuncová, M.Is profitability a good proxy for efficiency? Evidence from the subsector of tour operators. Review of Economic Perspectives Národohospodársky Obzor. Vol. 17, No. 4, pp. 425-440, (2017)

[25] Cannon, C. M. Profitability Calculations and Business Practice: An Inquiry Into Academic and Business Stereotypes. The Journal of Industrial Economics, Vol. 15, No. 3 (Jul. 1967), pp. 189-199. (1967)

[26] Illés, M. A gazdaságossági és jövedelmezőségi számítások alapjai. (Fundamentals of profit requirements and business efficiency calculations.) Szakszervezetek Gazdaság és Társadalomkutató Intézete, Budapest. (1990) 